\title{
Capturing the Motion of the Free Surface of a Fluid Stored within a Floating Structure
}

\author{
Roman Gabl ${ }^{1,2, * \mathbb{D}}$, Jeffrey Steynor ${ }^{1}$, David I. M. Forehand ${ }^{1}$, Thomas Davey ${ }^{1}{ }^{\mathbb{C}}$ and Tom Bruce ${ }^{1}$ \\ and David M. Ingram ${ }^{1}(\mathbb{D}$ \\ 1 School of Engineering, Institute for Energy Systems, FloWave Ocean Energy Research Facility, \\ The University of Edinburgh, Max Born Crescent, Edinburgh EH9 3BF, UK; Jeff.Steynor@ed.ac.uk (J.S.); \\ D.Forehand@ed.ac.uk (D.I.M.F.); Tom.Davey@flowave.ed.ac.uk (T.D.); Tom.Bruce@ed.ac.uk (T.B.); \\ David.Ingram@ed.ac.uk (D.M.I.) \\ 2 Unit of Hydraulic Engineering, University of Innsbruck, Technikerstraße 13, 6020 Innsbruck, Austria \\ * Correspondence: Roman.Gabl@ed.ac.uk
}

Received: 06 December 2018; Accepted: 22 December 2018; Published: 29 December 2018

\begin{abstract}
Large floating structures, such as liquefied natural gas (LNG) ships, are subject to both internal and external fluid forces. The internal fluid forces may also be detrimental to a vessel's stability and cause excessive loading regimes when sloshing occurs. Whilst it is relatively easy to measure the motion of external free surface with conventional measurement techniques, the sloshing of the internal free surface is more difficult to capture. The location of the internal free surface is normally extrapolated from measuring the pressure acting on the internal walls of the vessel. In order to understand better the loading mechanisms of sloshing internal fluids, a method of capturing the transient inner free surface motion with negligible affect on the response of the fluid or structure is required. In this paper two methods will be demonstrated for this purpose. The first approach uses resistive wave gauges made of copper tape to quantify the water run-up height on the walls of the structure. The second approach extends the conventional use of optical motion tracking to report the position of randomly distributed free floating markers on the internal water surface. The methods simultaneously report the position of the internal free surface with good agreement under static conditions, with absolute variation in the measured water level of around $4 \mathrm{~mm}$. This new combined approach provides a map of the free surface elevation under transient conditions. The experimental error is shown to be acceptable (low mm-range), proving that these experimental techniques are robust free surface tracking methods in a range of situations.
\end{abstract}

Keywords: free surface measurement; optical motion capturing; tank test; wave gauge; sloshing

\section{Introduction}

Designs for floating structures that hold internal fluids with a free surface must be capable of withstanding both the internal and external fluid pressures. The movement and stability of the structure is also affected by both fluid bodies. To investigate these effects, researchers must quantify sloshing within a free floating structure, which requires new methods of free surface tracking that are robust and repeatable. It is important that these measurement techniques are benchmarked and quantitatively understood if employed to quantify the free surface in experimental investigations that will be used to validate numerical methods for predicting such interactions, especially with larger motions.

Comparable research questions on the interaction between two separated water bodies can be found in oscillating water column (OWC) wave energy converters [1,2] as well as in ship design [3-5], especially in connection with the transport of liquefied natural gas (LNG) [6]. Sloshing experiments are an essential part of the design process, a problem typically explored using closed tanks mounted 
on motion platforms [7-9]. In most cases, such investigations focus on the impact forces exerted on the walls with respect to different filling levels. Hence, pressure transducers are the key measurement instrument [10-12].

For very large floating structures (VLFS), experimental data and numerical solutions are available, which investigate the deformation of VLFS depending on different mooring types [13-15]. Lee et al. [16] included multiple inner tanks filled with water in a VLFS and presented a numerical approach based on finite element method. This approach exhibits good agreement with experimental data but is limited to small motions. An example application of the full-scale structure would be as buoyant energy storage $[17,18]$. The size of such a device is comparable to ships and large platforms.

The motion of the free surface is a key indicator used in the comparison of experimental results and numerical simulations. The precision and accuracy of the free surface measurement is important in the validation of the numerical results. In general, a high spatial density of measurement points from two different and ideally independent systems is preferable to provide redundancy and reduce uncertainty [19]. It is also important that any additional mass on the model be minimised so that mass balance is not affected by the instruments. Finally, the movement of the floating tank should not be impeded by the experimental and measurement systems.

Classical approaches to detect and follow free surfaces are based on surface piercing wave gauges [20-25] or ultrasonic/acoustic probes, which measure the delay of the ultrasonic signal echo caused by the density change at the free surface $[26,27]$. Submerged acoustic instruments can measure the fluid velocity beneath the free surface at laboratory scale $[28,29]$ as well as for field applications [30]. Such point measurement devices are very robust and precise. The observation of visible markers is an option for laboratory experiments [31,32] and can also be applied for field measurements [33].

Gomit et al. [34] present a method to detect the free surface depending on the 2D velocity field in a towing tank. In that case, a horizontal laser sheet is observed by up to three cameras and this requires optical access from the bottom of the tank. Similarly, vertical laser sheets used for particle image velocimetry (PIV) can be applied to measure the velocities as well as to detect free surfaces [35-40]. Belden and Techet [41] combined this method for air and water to detect the surface. These mentioned approaches are limited to a two-dimensional section, which results in a single slice through the surface and delivers results similar to a Light Detection And Ranging (LIDAR) measuring system [42,43]. Weitberecht et al. [44] evaluate the accuracy of surface PIV, which use the free water surface as measurement plane without a laser. In this case the water depth is comparably shallow (approximately $4.6 \mathrm{~cm}$ ) and the measurement of velocity vector field base on particles seeded continuously onto the water surface. Comparable big motion of the free surface in sloshing tanks leads to a high rate of mixing, which makes it harder to maintain the particle distribution. Akutina et al. [45] capture the movement of neutrally buoyant particles and address the problem of the measurement validation as well as reduce the influence of optical distortion.

Evers and Hager [46,47] present an approach to capture the curvature of the water surface caused by an impulse water wave in a tank. In their method, a light grid is projected on the free surface and the deformation is captured with cameras. The 2D images of the grid deformation are then transformed into a calculated 3D surface. This approach requires the addition of pigment to the water $[48,49]$, which is unlikely to be a viable option when extending the approach to a large wave basin. Additionally, the floating structure would shadow the free surface and hence measurement near the structure walls would not be possible.

This paper presents a new approach to capture the free surface motion inside a floating tank with bespoke floating markers using a 3D motion capturing system. Comparable wave gauges have been previously used in wave run-up experiments on a slope [38,50,51] or on fixed cylinders [52] but in these cases the wave gauges were always stationary. Wave gauges made of copper tape are also investigated to determine if the water run-up within or around a floating body can be captured accurately even if the body orientation changes in relation to its initial configuration. Experiments with an open-top clear acrylic cylinder filled with water (Figure 1) under static and transient conditions have been 
conducted. The aim of this work is to evaluate these two approaches for a use in combination with a floating structure.

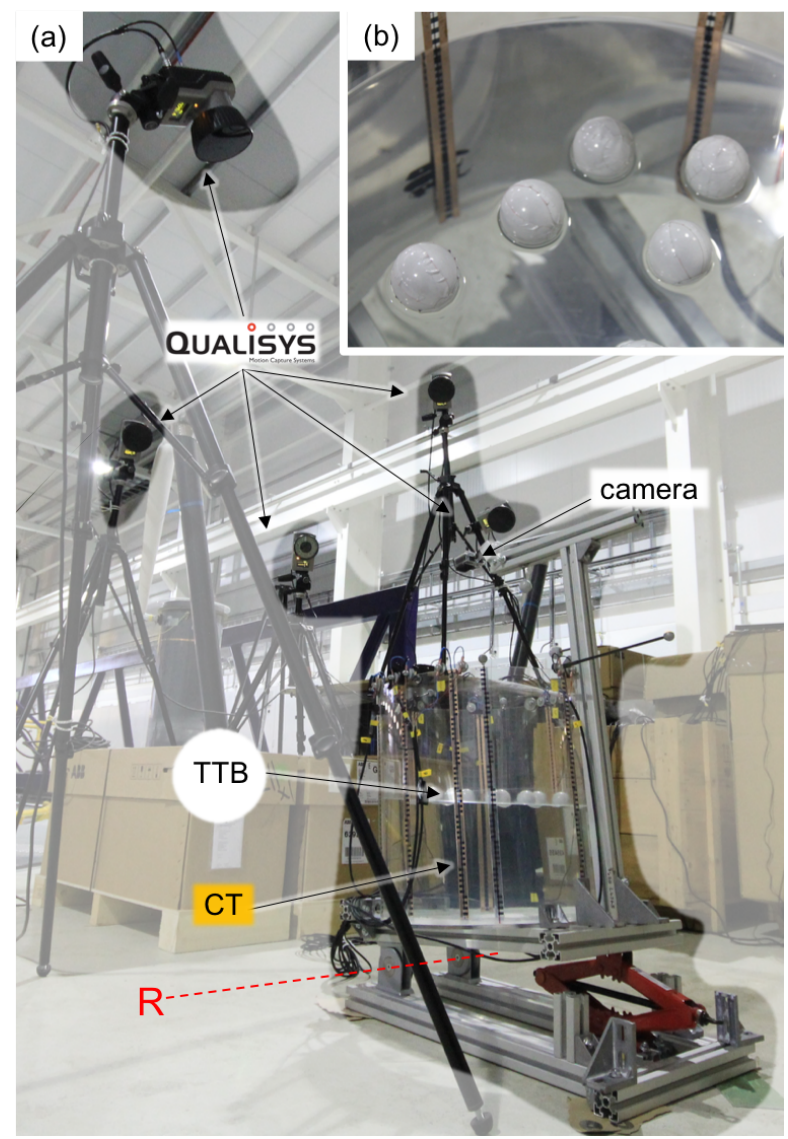

Figure 1. Experimental set-up—acrylic cylindrical tank mounted on an inclinable framework including table tennis balls (TTB) and wave gauges made of copper tape (CT) -rotation axis $R$-(a) overview of the inclined structure and (b) detail of the inner water surface.

\section{Experimental Method}

\subsection{Overview}

A cylindrical tank with an inner diameter $D$ of $0.49 \mathrm{~m}$ is investigated (Figure 1 ). The transparent acrylic structure has a material thickness of $5 \mathrm{~mm}$ for the cylinder walls and $7 \mathrm{~mm}$ for the floor plate. If the cylinder is filled to its maximum height $H$ of $0.5 \mathrm{~m}$, it contains $94.28 \mathrm{~L}$ of water, ignoring any errors in circularity. For the presented experiments, the tank is fixed on a framework (rather than free floating), which allows an inclination around one fixed rotation axis $R$ (Figures 1 and 2). The position of the structure is determined by a four camera Qualisys motion capturing system.

The water level in the tank is given by a measurement scale on the cylinder wall and captured by a camera, which is mounted at a constant position relative to the opening of the cylinder (Figure 1). This is used as a reference for the two measurement methods under investigation for the free surface motion: (a) floating infra-red reflective markers (Section 2.2) and (b) wave gauges made of conductive copper tape (Section 2.3). The first approach is based on the motion capturing system and is a new implementation, which enables this system to also capture a changing water surface. The investigation also aims to demonstrate that wave gauges made of light weight copper tape can be bonded to a moving body and deliver reliable measurements under different inclinations without the need for a recalibration. 


\subsection{Floating Infra-Red Reflective Markers}

The movement of the containing cylindrical tank is captured with a commercial optical motion capture system from Qualisys. All six degrees of freedom (DoF) are determined based on the relative position of the markers, which are mounted on the rigid acrylic structure [53-56]. The Qualisys system is also capable of simultaneously tracking multiple independently moving reflective markers in the three translational degrees of freedom. Hence, the possibility of capturing the free water surface with additional floating markers randomly located inside the structure can be explored.

All known commercially available passive spherical reflective markers are either not suitable for wet conditions (i.e., they lose their reflectivity) or are not buoyant. Consequently, a bespoke solution is chosen to make each floating reflective marker from a standard table tennis ball. The table tennis ball (mass of $2.7 \mathrm{~g}$, diameter $40 \mathrm{~mm}$ ) serves as the basic body, which has enough buoyancy and visibility for the application. Reflective tape is applied to provide the reflectivity to infra-red light. This set-up is comparable to the taped underwater markers offered by Qualisys, but much lighter, water resistant and buoyant. A preliminary feasibility study showed that such a marker ball can be tracked by the Qualisys system whilst afloat on the surface and subject to wave motions in the University of Edinburgh's Curved Wave Tank [57] and in the FloWave basin, which has a diameter of $25 \mathrm{~m}$ and is also located at the University of Edinburgh [58-63].

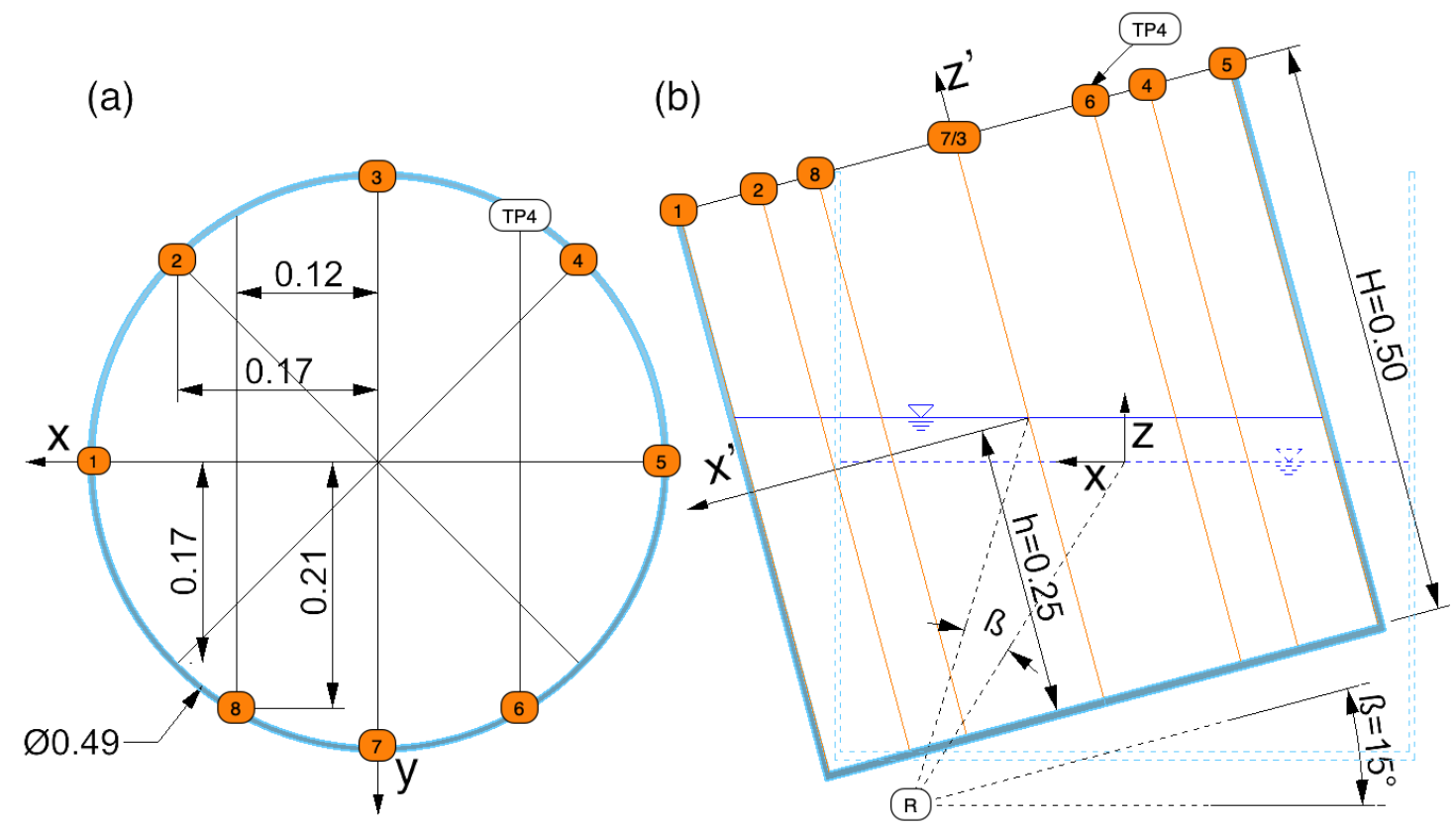

Figure 2. Basic geometry (a) plan view of the upright cylinder including the numbering of the wave gauges and (b) side view of the inclined geometry with an example pitch angle $\beta-R$ is the rotation axis and TP4 the reference point introduced in Section 3.2-all dimensions in [m].

For the experiments, 12 marker balls are added to the water in the circular tank (Figure 1). They are left to freely float on the surface and are captured simultaneously with the rigid body markers. By distributing the balls well over the entire surface, nearly no clustering effects were observed. In the rare case that the balls do cluster, the system is capable of identifying correctly up to three markers, which may be in contact with each other. In post-processing, the markers have to be separately identified as the software cannot automatically recognise them. This is only possible for rigid bodies with a fixed distance between multiple markers. The identification of the marker balls has to be done only once for each measurement and further tracking is done automatically by the software. Alternatively, all unidentified trajectories can be exported and processed with additional software 
(for example Matlab). In this case, the initial fill level inside the cylinder can be chosen to autonomously identify the markers and separate from those, which are attached to the body.

As shown in Figure 1, the Qualisys system includes one Oqus 210c for video capturing and four Oqus $300+$ cameras for marker tracking. The capture rate was set to $100 \mathrm{~Hz}$ for all tests.

Two sets of results from the motion capture system are presented here: (a) definition of the 6 DoF motion of the rigid body and (b) the coordinates of the free floating markers, which are recorded relative to the global coordinate system.

\subsection{Copper Tape Resistive Wave Gauges}

Wave gauges are a very reliable and accurate measurement system to detect and record the motion of water free surfaces. They are standard measurement instruments in tank testing [64] and can also be used under very complex conditions $[38,50,59,60,65]$ as well as near submerged structures $[21,22,66,67]$. This measurement system correlates the resistance between two parallel rods with the submerged water depth. A direct electric current would lead to an anode/cathode arrangement leading to removal of ions in the water surrounding the gauges [20]. Hence the amplifier sends an AC signal with a typical excitation frequency of $10 \mathrm{kHz}$ [68]. In general, the specification of such a wave probe depends on the application as well as the maximum expected wave amplitude. Typically heights vary between 0.3 to $1 \mathrm{~m}$ with a rod diameter of 3 to $4 \mathrm{~mm}$ [68], but thinner wire can be utilised if necessary. Andresen and Frigaard [69] applied wave gauges made of a wire with $1 \mathrm{~mm}$ near a cylinder under wave conditions and even thinner, namely 0.13 and $0.4 \mathrm{~mm}$, are used by Liu et al. [70] in a wind-wave tank.

In the case of a tank test the typical accuracy of the conductive probes are in the range of $\pm 0.25-0.5 \mathrm{~mm}$ respectively $0.1 \%[64,68]$. Similar ranges of accuracy, namely $\pm 0.3 \mathrm{~mm}$, can be achieved by for ultrasonic sensors for experimental conditions as presented by Longo [28]. In the case of aerated and breaking wave this range has to be expanded. An accuracy of $1 \mathrm{~mm}$ is found by Gomit et al. [34] for the measurement of the crest with a resistive probe made by HR Wallingford. Petti and Longo [71] corrected the systematic error in the swash zone between the actual front on the beach in relation to the measurement by the run up wire with a separate video observation. A fixed offset of $5 \mathrm{~mm}$ was found as a good compromise to reduce the geometrical error without excessive signal error [71]. Whittaker et al. [51] quantify the accuracy for runup experiments with $\pm 2 \mathrm{~mm}$ in the vertical direction based on effects of surface tension and calibration.

At the outset, the possibility of using conductive paint was investigated as part of preliminary tests. Those proved that it is possible to fabricate wave gauges by drawing on a surface with conductive paint (MG Chemicals 842AR-P Conductive Pen Silver). The hand drawn wave gauge was connected to the standard Edinburgh Designs' wave gauge box. Despite that the application with this method is inaccurate, the technique is very flexible and can be used in the future for specific applications that limit the use of tapes and rods. When dry, the conductive paint is water-resistant but remains very delicate and subject to mechanical damage. The variable cross section of the conductive paint leads to a non linear variation in gauge resistance that is not easily quantified, and therefore is only recommended for discrete water level measurements.

Based on their robust and exact mounting in comparison to the conductive paint, wave gauges made of copper tape were chosen [51,52]. Previous applications of such a tape can found as a switch [72,73] to indicate discrete water levels. In another study, Heller and Spinneken [38] bonded stainless steel strips on the surface of the inclined walls. For the current project, the scale for the water level inside the tank was used as an alignment for the conductive tape on each side. Separations of $30 \mathrm{~mm}, 24 \mathrm{~mm}, 20 \mathrm{~mm}, 15 \mathrm{~mm}, 10 \mathrm{~mm}, 5 \mathrm{~mm}, 4 \mathrm{~mm}$ and $1 \mathrm{~mm}$ between the $6.25 \mathrm{~mm}$ wide copper tapes were investigated. Preliminary dip tests showed that very small spacings between the two tapes lead to a delayed response to water level changes due to residual water films reducing the gauge resistance. Greater separations reduced the potential for stray conductive paths resulting from the residual water films that had led to erroneous measurements. Smaller separations provided a better signal to noise ratio and a reduced error in detecting oblique water surfaces run up. The $5 \mathrm{~mm}$ separation was 
chosen as the distance between the two tapes, resulting in a centerline separation of $w=11.35 \mathrm{~mm}$. Whittaker et al. [51] used a bigger spacing of $20 \mathrm{~mm}$. As part of the current tests, the durability of wave gauges based on conductive tape could be shown for normal laboratory conditions.

One Edinburgh Designs WG8USB Wave Gauge Controller is used for the presented work. The sample rate is $128 \mathrm{~Hz}$ [68]. Figure 2 shows the location of each wave gauge. In total, all the available 8 gauges are used, which is the capacity of a single controller. The rotation axis $R$ for the following presented experiments (Section 3.2) is parallel to the $y$-axis. The wave gauges are arranged in four pairs with equal distance to the $y$-axis. In addition to the quadrants, the two wave gauges WG2 and WG4 are located at octants and have the equal $|x|$ and $y$ distance of $D /(2 \cdot \sqrt{2})=0.173 \mathrm{~m}$. With an $|x|$ coordinate of $D / 4$ for the WG6 and WG8, the $y$-value is $D \cdot \sqrt{3} / 4=0.212 \mathrm{~m}$. For the evaluation of the inclination tests an additional marker TP4 (tank point, Figure 2 ) is needed. The $[x, y, z]$-coordinates of this point are $[-D / 4, D \cdot \sqrt{3} / 4, H-h+d h]$ with an offset $d h$ of approximately $10 \mathrm{~mm}$ and height of the cylinder $H$ of $0.5 \mathrm{~m}$. The origin of the local coordinate system is located in the centre of the tank and on the initial water level $h$ of $0.25 \mathrm{~m}$. The measurements of the Qualisys system are based on a different global coordinate system, which is defined as part of the calibration. The results are transformed into a local coordinate system, which has its origin at the tank point TP4 (Figure 2).

\section{Results}

\subsection{Influence of Variable Inner Water Depth $h$}

In the first phase of the investigation, different water levels are measured with both methods to quantify the differences between the two approaches. For this set of tests, the location of the cylinder is fixed in the stationary position and the volume of fluid inside the tank is changed. This investigation is similar to the required calibration of the WGs and to the application of wave run-up experiments $[38,51,52]$. Consequently, the measurements at the WG can be used to verify the new approach based on the floating markers.

A total of 50 different steady states are investigated. The observed value is the change in water depth $\Delta h$ inside the tank. The zero/reference value is set to the initial water depth $h=0.25 \mathrm{~m}$. Both investigated measurement systems are calibrated independently and all depths are verified with a scale inside the tank captured by a camera.

All measurements for this variation of the water level, as well as the inclination tests in Section 3.2, are repeated three times and include $20 \mathrm{~s}$ recording time for each. One data point in Figure 3 represents the mean value over the entire test duration for all of the repetitions, for all eight wave gauges. The same averaging techniques are applied to the $z$-coordinate results of the Qualisys system for all 12 markers.

In Figure 3a the measurements are directly compared (in $\mathrm{mm}$ ). Ideally, both measurement systems would report the same results. The absolute differences in Figure $3 \mathrm{~b}$ indicates that the measurement based on the balls has a tendency to underestimate the height. For most of the cases, the differences are in the range of $4 \mathrm{~mm}$ and only a smaller water depth results in an increase up to around $7 \mathrm{~mm}$. It is assumed that the influence of potentially biased measurements through the transparent cylinder is increased with a lower water level. The repetition of the $\Delta h$ equal $0 \mathrm{~mm}$ allows checking for such a potential time-dependent effect. Theses repetitions were conducted spread over the whole experimentation by starting with this water level, which is first increase up to maximum, than reduce to the minimum level and back to the starting value of $\Delta h$ equal $0 \mathrm{~mm}$. A detailed analysis of those runs indicates two very good agreements near to the calibration process and the following repetitions have an increased difference. A change of the air temperature over the experimental time may cause an additional uncertainty in the water temperature of the comparably small volume in the cylinder and the used set-up (Figure 1).

In the case of the wave gauges made of conductive tape, the minimum standard deviation (of all eight wave gauges and three repetitions each $20 \mathrm{~s}$ long) can be found around the zero value. For both 
increasing and decreasing water levels, the standard deviation value increases up to an approximate value of $\pm 3 \mathrm{~mm}$ (Figure 3c). For the standard deviation of the measurements based on the Qualisys system (Figure 3d), such a clear trend cannot be found in relation to $\Delta h_{Q^{-v}}$ alues, hence there is no connection between the system calibration and its origin. The reduction of the standard deviation for the highest water depths in the tank can be explained by improved marker visibility. In general, the standard deviation is in the same range as the observed absolute differences between the two measurement systems.
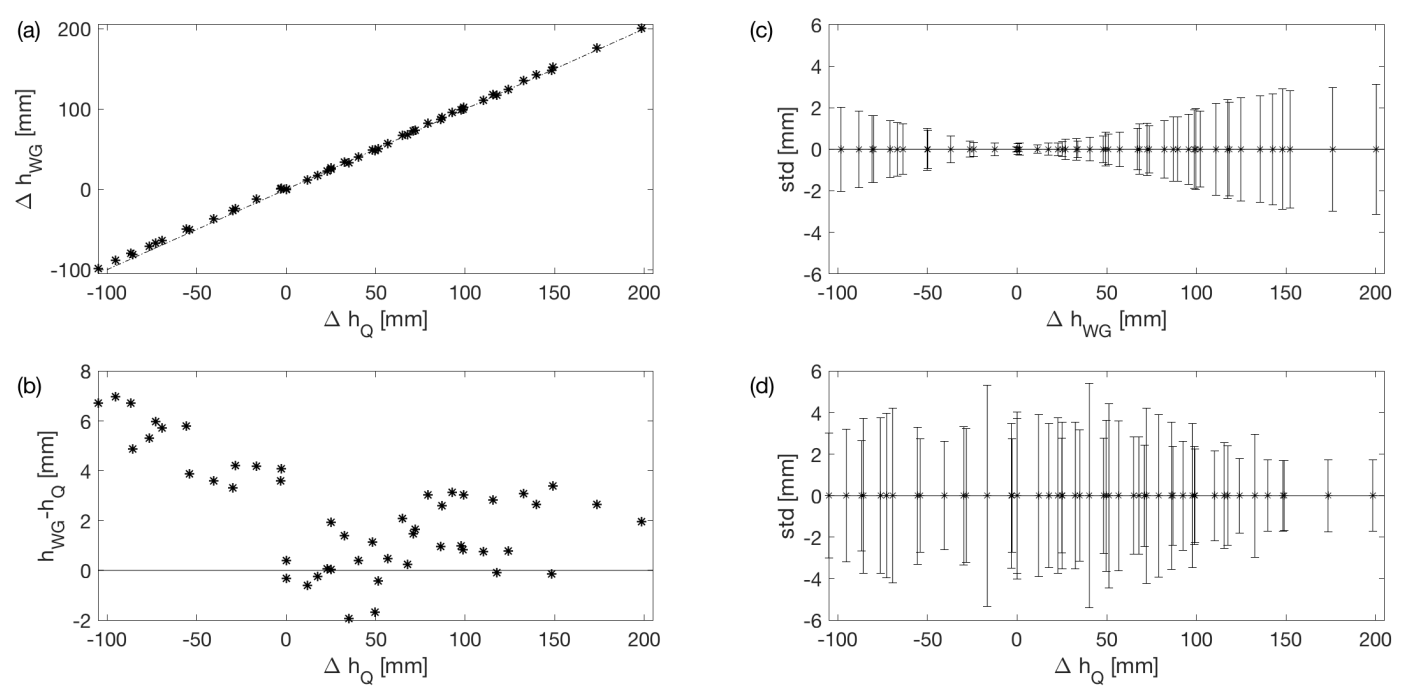

Figure 3. Comparison of the methods with a variable water depth $h$ inside the cylinder-(a) comparison between water depth captured with the marker balls via Qualisys (Q) and wave gauges (WG); (b) absolute differences between the methods; (c,d) standard deviation (std) for each method.

Whittaker et al. [51] quantified the accuracy of this method with approximately $\pm 2 \mathrm{~mm}$ in the vertical direction for a run-up experiment, which seem to be also applicable for the wave gauges made of copper tape. It seems to be reasonable to double this value for the floating balls based on the bigger standard deviation as well as the absolute differences between the two methods. On this basis, the next step is to investigate an inclined body in Section 3.2.

\subsection{Influence of Variable Inclination Angle of the Tank}

A fundamental difference between the two measurement systems is their point of reference. The locations of the infra-red markers are captured and reported based on a global reference frame which is independent of the position of the cylinder. The wave gauges are directly connected to the cylinder and thus measure the free surface in the local frame of reference of the cylinder. In contrast to the previous applications of onshore wave run-up probes [38,51,52], the orientation of the WGs changes according to the movement of the body on which they are bonded. Those tests allow to explore whether this effect on the measurement is significant or not.

It is necessary to transform the position of the floating markers to the local frame of reference of the cylinder or transform the wave gauge results into the global coordinate system. The required rotation matrix and the position vector is provided by the motion capturing system.

Figure $4 \mathrm{a}$ shows the mean value of the measurements of the two wave gauges laying on the $y$-axis (WG3 and WG7) vary with the rigid body's pitch angle as captured by Qualisys $\left(\beta_{Q}\right)$. In the case of a rotation around the $R$-axis, which is parallel to the rotation axis $y$, those values should remain at $0 \mathrm{~mm}$ as well as the global mean value over all eight wave gauges. The other pairs of wave gauges (namely WG1 \& WG5, WG2 \& WG4, WG6 \& WG8) are analysed in Figure 4b. The absolute distances in the $x$-direction for each pair is equal. Consequently, the mean value of each pair should also be 
$0 \mathrm{~mm}$. Both analyses indicate that with an increasing $\beta_{Q^{-}}$-angle, a bigger difference to the theoretical position also occurs. This is possibly due to deformation of the structure resulting in a decrease in cross-sectional area, in turn increasing the height of the fluid in the structure. This will not be an issue for structures tested in the wave tank, as the surrounding water pressure will counteract the inner pressure.

The results of the three pairs of wave gauges with an $x$ offset are used to back calculate the inclination of the structure $\beta_{W G}$, which should be identical to the pitch angle $\beta_{Q}$ measured by the Qualisys system. Figure $4 \mathrm{c}$ presents the direct comparison of those values and Figure $4 \mathrm{~d}$ the differences. A calculation of the inclination based on the wave gauge data would result in an under prediction of approximately $1^{\circ}$.

For the analysis of the measurements based on the marker balls, the vertical transition caused by the rotation has to be included. Basic geometric dependences are shown in Figure 2 for the centre point on the water surface. A theoretical height increase $z_{Q, t}$ is calculated to compare the observation $z_{Q}$ of the markers. The value $z_{Q, t}$ depends on the measured pitch angle $\beta_{Q}$ of the cylinder and the exact position of the rotation axis $R$. It is assumed that the rotation axis $R$ is parallel to the $y$-axis, and to specify the location of the axis $R$, a circle is fitted through the measured $x$-and $z$-coordinates of the tank point TP4.
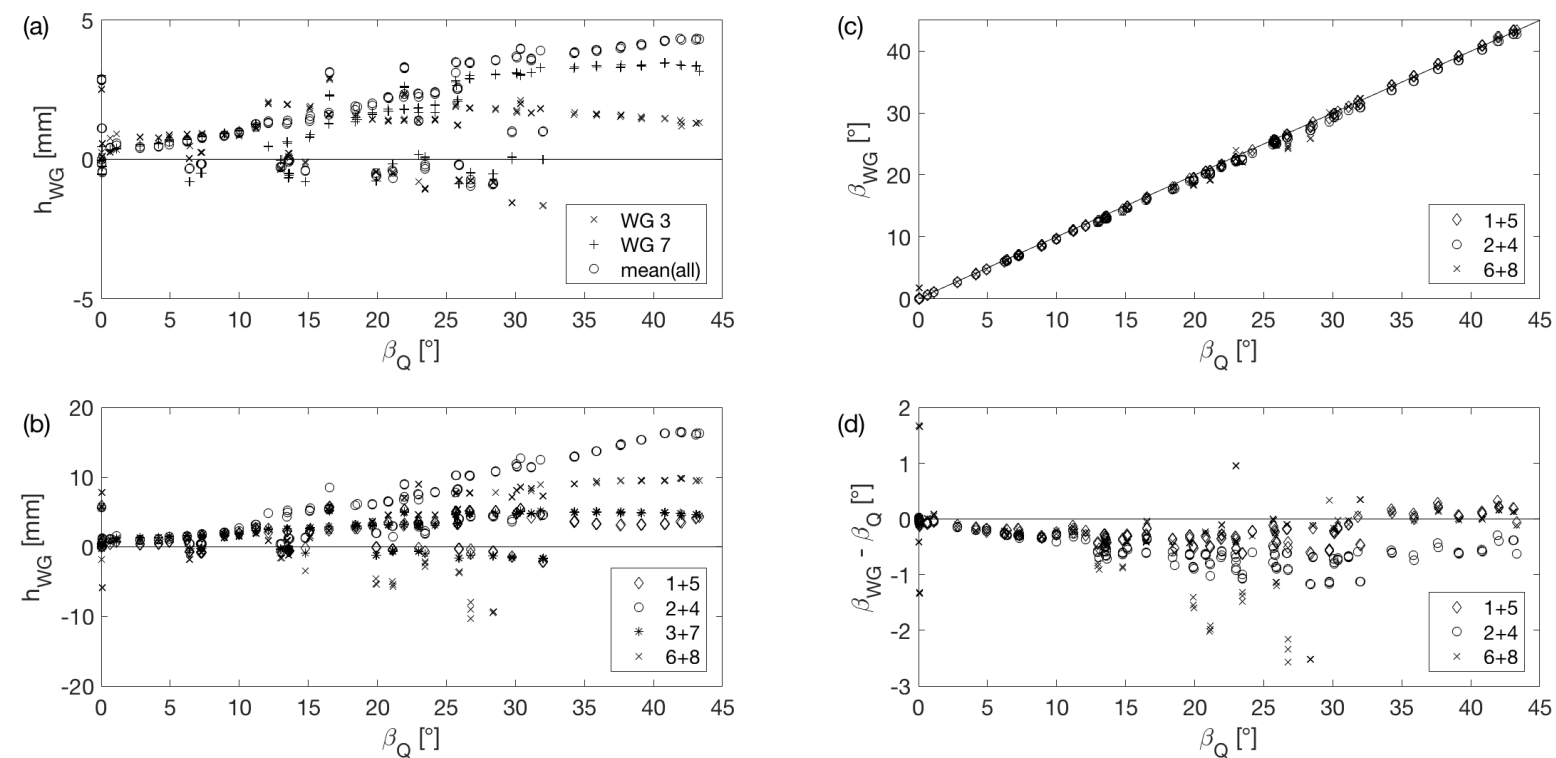

Figure 4. Influence of variable pitch angle $\beta$ on the wave gauges (WG) - $(\mathbf{a}, \mathbf{b})$ analysis of the measured changes in the free surface; (c,d) comparison between the measured angle $\beta_{Q}$ and the calculated $\beta_{W G}$ based on the wave gauges pairs.

Figure 5a allows a comparison of the theoretical and measured values for the water surface and tank point TP4 in relation to the angle $\beta_{Q}$ of the body. All values are transformed so that $0 \mathrm{~mm}$ indicates the initial water surface. The absolute differences between calculated and measured values are shown in Figure $5 \mathrm{~d}$. Both graphs indicate that, in a range of $\beta_{Q}$ up to $30^{\circ}$, the theory over-predicts the measurement and beyond that point it under-predicts.

For a further analysis, the same data-set is plotted in relation to the measured roll angle $\alpha_{Q}$ in Figure $5 \mathrm{c}$ and the yaw angle $\gamma_{Q}$ Figure 5e. A comparable behaviour to the angle $\beta_{Q}$ could be found for $\alpha_{Q}$ around $1^{\circ}$, but not for $\gamma_{Q}$. This indicates that the complete system is not completely rigid and includes a small inclination around the $x$-axis and a part of the differences can be explained as a result. The standard deviation of the measurements of the marker balls (Figure $5 b$ ) show the same range as found by changing the water level $h$ inside the tank (Figure 3d; Section 3.1). 
The results of both stationary cases, namely the set of measurements with changing inner water level and variable inclination of the tank, show a reasonably small error of a few millimetres for each measurement system. The possible over-prediction of the water level in the case of inclined wave gauge in relation to the water surface should be considered for further comparisons with numerical simulations. Circularity measurements may verify if the increase in water level is due to deformation of the structure or a wave gauge error.
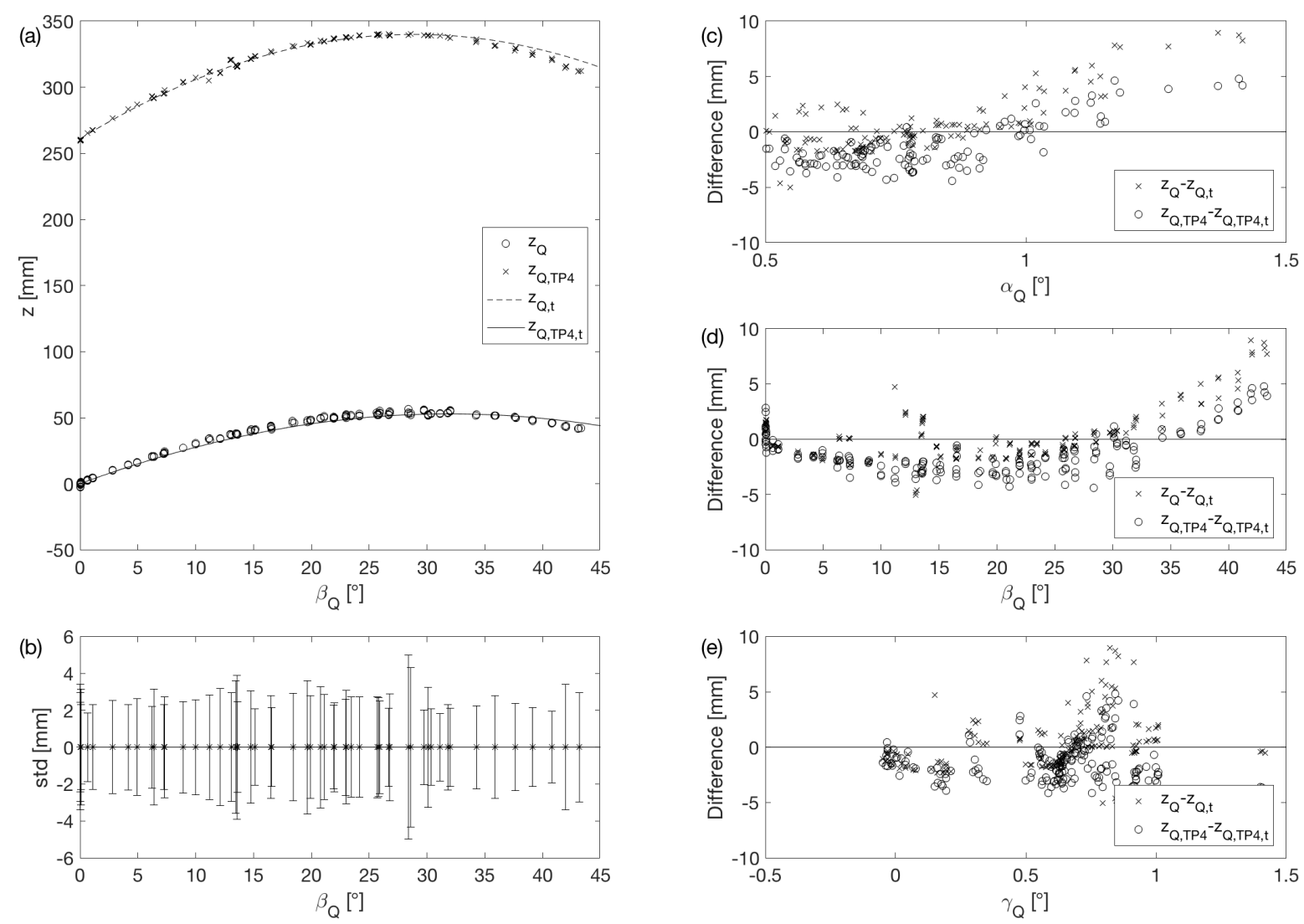

Figure 5. Influence of variable pitch angle $\beta$ on the floating markers-(a) comparison of the theoretical with the measured $z$-coordinate of the reference point TP4 and the free surface; (b) standard deviation of the measured balls; (c-e) absolute difference of the $z$-coordinate in relation to all three rotation axes.

\subsection{Transient Behaviour}

The previous investigations assume steady-state conditions and focused on establishing a proof of concept for the adapted measurement system. However, the goal is to investigate the free floating structure motions and inner free water surface when influenced by periodic wave conditions in a wave tank. In this case the free water surface inside the cylinder will be non stationary. Different drop tests are conducted to show that both measurement concepts are capable of capturing transient water surfaces inside of the tank. To achieve this, the cylinder is fixed in an inclined position and the supporting mechanism is suddenly removed. Hence, the tank falls onto an end stop and the oscillation of the free surface inside the tank is stimulated.

The presented experiment is chosen because a small overtopping volume is provoked near the wave gauge $W G 1$. Figure 6 shows the rotation from an initial pitch angle $\beta_{Q}$ of $21.1^{\circ}$ to $6.4^{\circ}$. For the other two rotations, the observed differences $\Delta \alpha$ and $\Delta \gamma$ to the starting condition (inclined cylinder) are very small. All systems are synchronised so that the approximated start of the movement is at $t=0.25 \mathrm{~s}$. The end position of the structure has an inclination in pitch caused by the end stop, which is added to the framework. The first impact compresses this end stop and a nearly stable situation of 
the cylinder is reached after about one second. A small periodic movement of the structure is also observed, which is caused by the moving water body in the tank combined with the soft support of the end stop material.

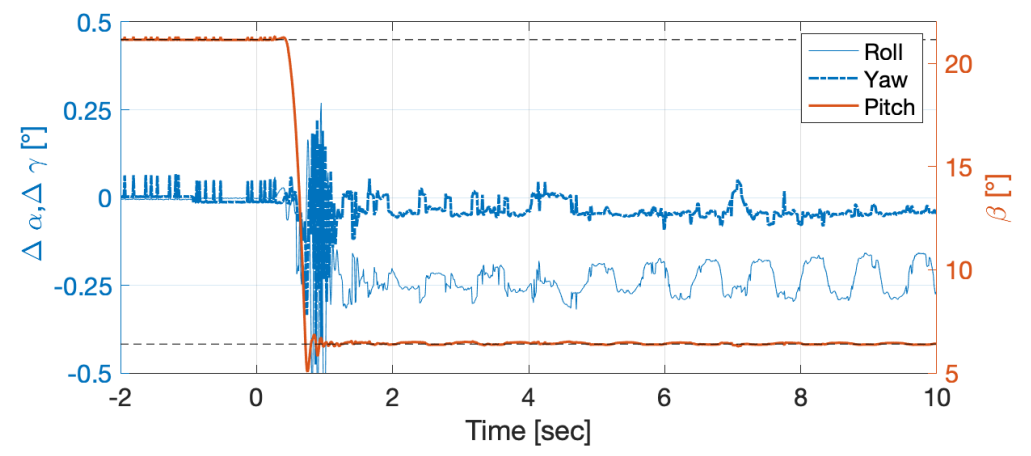

Figure 6. Measured angles of the rigid body caused by the sudden removal of the support structure.

Simultaneously two videos are captured, which give a very good overview of the behaviour of the water stored in the structure. The measured position of the markers can be directly connected with the video from the Oqus 210c. In contrast to this fixed position of observation, the second camera on the framework moves with the structure. This allows comparison of the visible scale inside the cylinder with the captured free surface changes [7,31]. Different random samples are analysed as part of the plausibility check and demonstrate a very good agreement (typically in the low range of a few millimetres) between both experimental methods. Therefore, the global coordinates of the marker balls had to be transformed into the local coordinate system of the cylinder.

Figure 7 presents the results of the wave gauges for the drop test. In each graphic, each pair of wave gauges with the same $x$ offset are grouped, and the normalised water surface displacement $\eta / h$ is plotted as the $y$-value. This non-dimensional elevation is also used for the second and third row in Figure 8 (two different side views) for the following analysis of the floating markers. As mentioned, the initial water height $h=0.25 \mathrm{~m}$ is equal to half of the total height $H$ of the cylinder. The $\eta / h$ value equal to 1 [-] in the first big peak of the wave gauge WG1 indicates the overtopping at this part of the cylinder. A wave period of approximately $0.7 \mathrm{~s}$ is observed for the introduced oscillation. The final conditions also include an inclination due the end stop material, which is added to the support structure, which alters the resting position of the structure, affecting the final value of all wave gauges except WG3 and WG7 because they lie on the $y$-axis.

The results show that the main oscillation direction is at first aligned with the movement of the cylinder in the $x$-z-plane and changes after a few seconds to the orthogonal direction in the $y$-z-plane. The WG1 and WG5 show a damped oscillation with a nearly constant decrease of the amplitude. The peak values for $\eta / h$ at the WG3 and WG7 increase over the same time frame (Figure 7).

In addition to the wave gauge results, the elevation of each of the 12 free surface marker balls can be plotted. Figure 8 uses a different approach to show the three-dimensional motion of the markers. Four different time periods were chosen. For each period of record, the measured coordinates of all the 12 points were plotted in one graph. The top view (upper row) shows that the balls have the tendency to group together. Nevertheless, a good coverage is maintained. The side view of the first $5 \mathrm{~s}$ time period also captures the overflow with a $\eta / h$-value near to $1[-]$, which fortunately did not result in the loss of a marker. The change of the main oscillation direction can also be observed in the measured data of the marker balls (going from 3rd to 4th column in Figure 8).

This simplified transient experiment showed the capability of both methods to capture the free surface inside the cylinder. The advantages and limitations of each approach are discussed in the following section. 

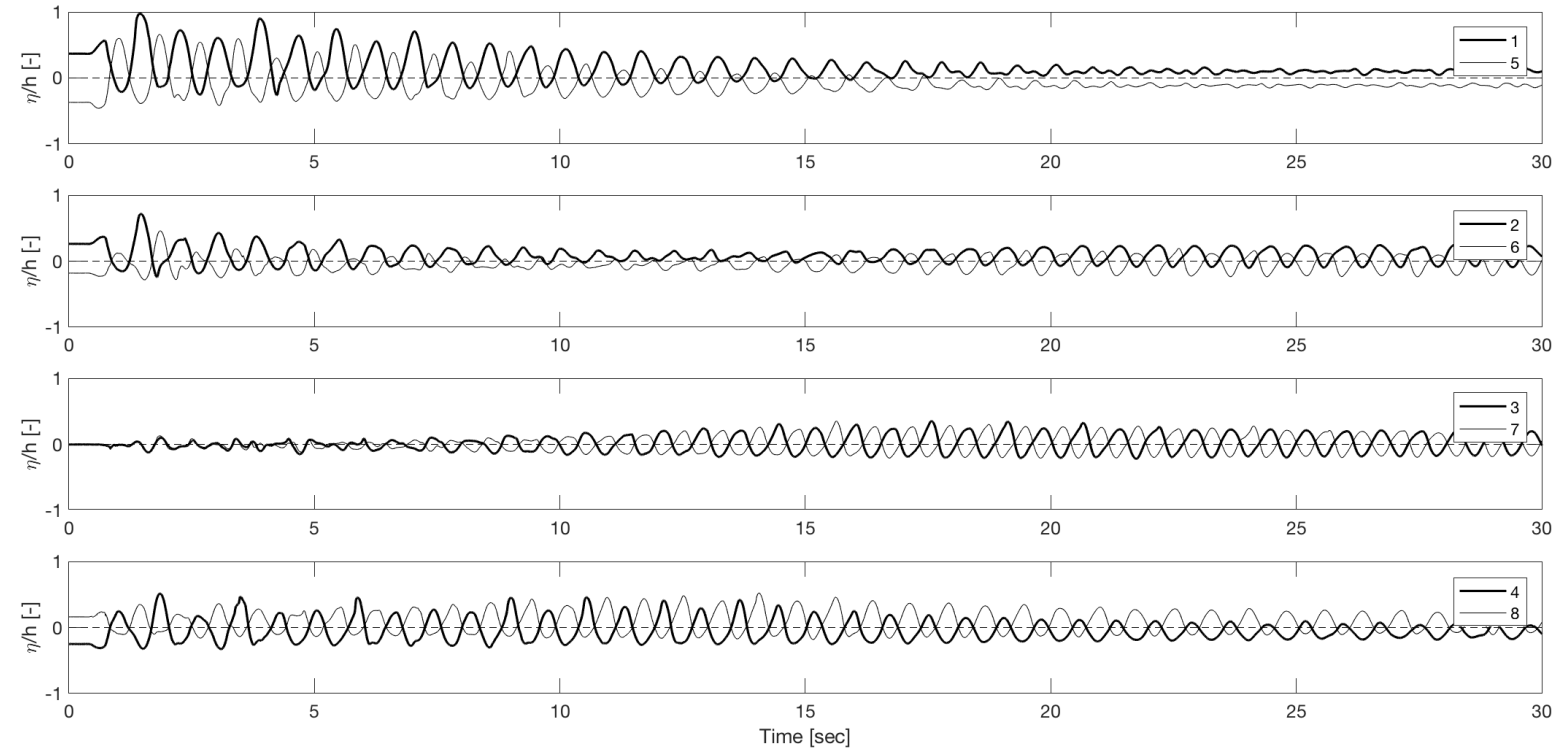

Figure 7. Results of the transient experiment-wave gauges (WG) in pairs as defined in Figure 2-normalised surface elevation $\eta / h$.
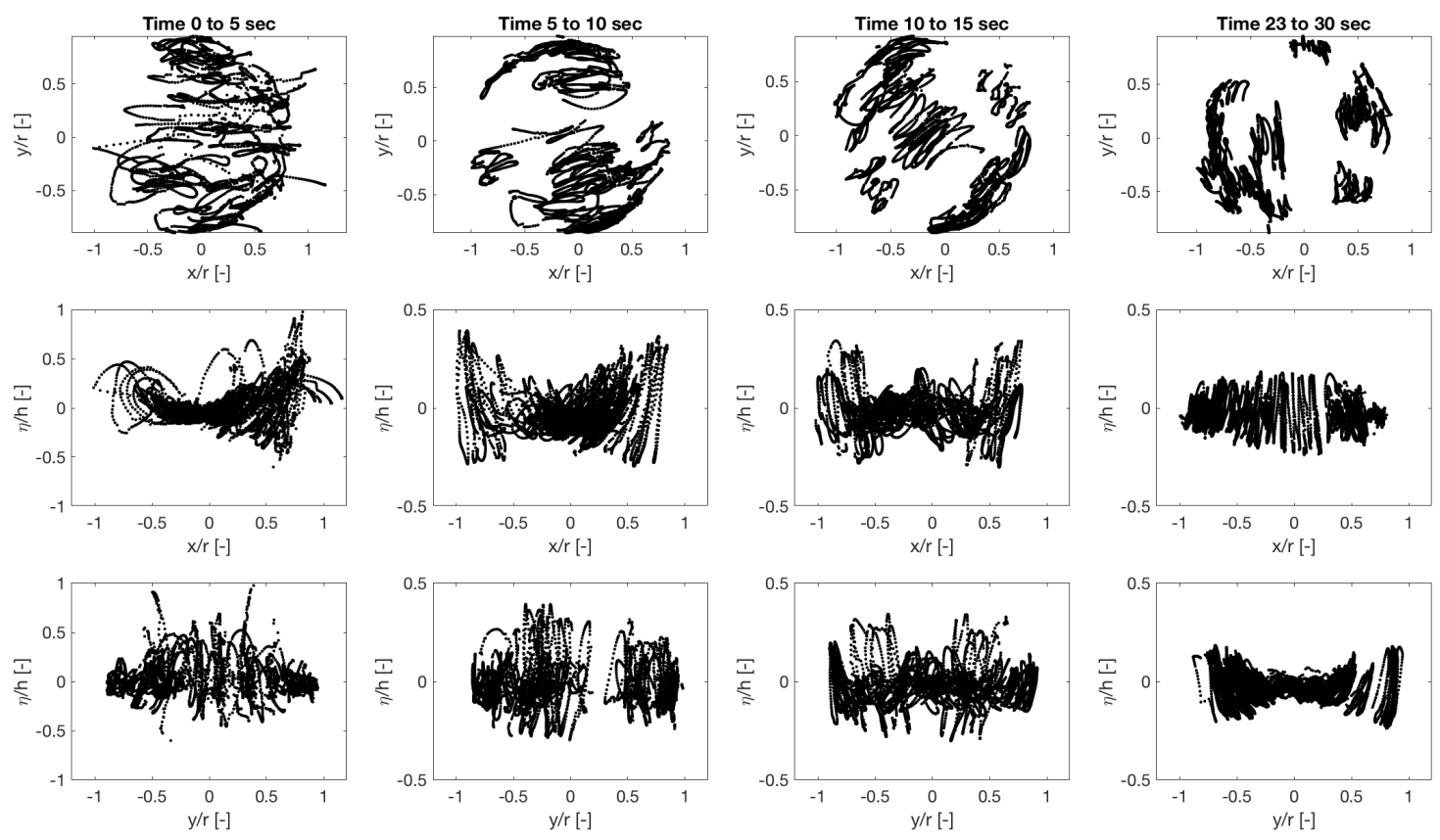

Figure 8. Results of the transient experiment-3D location of the measured marker balls; four different time periods (columns) and three different view directions (rows).

\section{Discussion}

Both measurement systems investigated here fulfill the basic requirements mentioned in Section 1 for the future use of capturing the motion of the free water surface inside a floating structure in a wave tank.

The addition of the bespoke marker balls into the tank is simple to implement, and makes use of the motion capture systems which are typical equipment in a laboratory with wave basins. Camera positions may have to be adapted and more carefully chosen, so that the inside of the floating cylinder is easily captured. A motion capture camera view from the top would be very advantageous for 3D capture of the markers, but this may not always be practical to realise. 
The floating markers are capable of surviving very rough conditions in the cylinder and are very light. It is thus assumed that the influence of adding floating markers to the free surface is very small, but it cannot be excluded completely. Specific experiments with and without the markers should be compared for the individual applications in the future. For the current project, 12 markers were utilized, which covered approximately $8 \%$ of the available surface inside the cylinder. More floating markers could be applied, but as a result the interaction between the markers would also increase. The ideal number and size of markers should be optimised for each project.

Under certain conditions the capturing of one individual marker's position is interrupted because fewer than two cameras detect it. This can be caused by obscuring components (such as the mounted camera at the top) or extreme sloshing, including breaking waves. There is also the possibility that one marker is washed out of the structure. This is an abort criterion because the water volume inside the tank is reduced in such a case. Overtopping of the structure cannot be captured with this measurement system.

The novel characteristic of this system is that the markers cover the free surface inside the cylinder (Figure 8), but the exact location cannot be predicted beforehand and is not repeatable. This situation can be improved with a splitting of the available volume inside the tank, for example with a vertical mesh. This can limit the area which each marker can cover but also has a further effect on the fluid dynamics. Conventional wave gauges could be a better option instead of such highly restricted markers.

The wave gauges made of the copper tape are fixed to the cylinder structure and no additional support structure is needed. This prevents unnecessary mass additions and subsequent changes in the centre of mass. An electrical connection is still required, but the cable can be added to the mooring lines required to stabilise the floating body. This solution requires an insulating and robust surface to apply the copper tape. A minimum distance between two pairs has to be maintained so that no interference occurs (similar to normal wave gauges). The capillary effect between the two tapes on the wall may lead to erroneous measurement. Based on a preliminary investigation, a distance of $5 \mathrm{~mm}$ was chosen for this investigation (Section 2.3). Such a suitable choice of the distance between the two electrodes helps to minimise this effect. Furthermore, maximum local water heights in the floating structure are caused by run up on the walls which is quantifiable with this method. If data analysis of the wave gauges is carried out in the local coordinates of the cylinder, no additional post processing is needed to use the measured data. The major disadvantage of video recording the scale inside the tank is the post processing required to attain useful data.

It is well known that the measurement method of wave gauges is highly dependent on the electrical properties of the water. The water for the tests herein was taken from the 2.4 million litre basin at FloWave and not fresh from the main water supply, thus minimising any temperature adjustments or other changes. In comparison to the wave tank, the stored water volume inside the cylinder (Figure 1) is very small. The changes of the air temperature over a working day also influenced the temperature of the water in the tank. Consequently, some of the observed errors may be caused by this change in environmental conditions and the (water) temperature should be measured in comparable investigations in the future. The temperature changes of the water in the wave tank under normal conditions is nearly negligible and hence the conditions for a submerged structure are far better than in the present configuration of being supported on a framework.

\section{Conclusions}

This paper presents two different measurement methods for capturing the motion of the free water surface inside a floating structure by re-purpose existing systems: (a) floating markers, which are captured in addition to the movement of the rigid body and (b) wave gauges made of conductive copper tape fixed to the walls of the cylinder. The additional mass of both systems is very small compared to the structure. Both systems are tested under laboratory conditions and their durability is shown. 
The conductive tape wave gauge proved very accurate and consistent in measuring the water height at the walls, where the maximum heights occur due to water run-up. It can be shown that the conductive tape wave gauges can also be applied to moving objects and that a change in the inclination in comparison to the calibration has a small effect on the accuracy. The standard deviation of the measurement system was found to be equal or smaller than $2 \mathrm{~mm}$ (variable water height, Section 3.1). Those measurements are directly connected to the movable structure, or local coordinate system. In contrast to this, the marker balls can freely float inside the water body and the measurement is in the global coordinate system. Hence the movement of the rigid body is captured in global coordinates, so that the free floating markers can be transformed into local coordinates for comparison with the copper tape wave gauge measurements. The standard deviation for this measurement system is in the range of $4 \mathrm{~mm}$ using markers with a diameter of $40 \mathrm{~mm}$ (Sections 2.2 and 3.1). A reduction of the marker size can result in a higher accuracy and should be considered in the future.

Different stationary and transient tests proved that both methods are capable of delivering measurements with a very high accuracy in low mm-range. The combination of both systems allows one to compare the two independent measurement methods and use the advantages of each approach. This has a significant benefit in providing useful data sets as a validation experiment for future numerical studies of free floating objects.

Author Contributions: R.G., J.S., D.I.M.F., T.D., T.B. and D.M.I. are responsible for the conceptualisation of the experimental investigation. R.G., J.S. and T.D. measured the data and analysed the data. R.G. and J.S. wrote the initial draft and D.I.M.F., T.D., T.B. and D.M.I. reviewed and edited the paper.

Funding: This research was funded by Austrian Science Fund (FWF) grant number J3918.

Acknowledgments: Further thanks go to the support team of Edinburgh Designs and Qualisys for their help.

Conflicts of Interest: The authors declare no conflict of interest.

\section{Abbreviations}

The following abbreviations are used in this manuscript:

LNG liquefied natural gas

Q Qualisys

VLFS very large floating structures

WG wave gauge

\section{References}

1. Chaplin, J.R.; Heller, V.; Farley, F.J.M.; Hearn, G.E.; Rainey, R.C.T. Laboratory testing the Anaconda. Philos. Trans. R. Soc. A 2012, 370, 403-424.

2. Farley, F.J.M.; Rainey, R.C.T.; Chaplin, J.R. Rubber tubes in the sea. Philos. Trans. R. Soc. A 2012, 370, 381-402. [CrossRef] [PubMed]

3. Hirdaris, S.E.; Bai, W.; Dessi, D.; Ergin, A.; Gu, X.; Hermundstad, O.A.; Huijsmans, R.; Iijima, K.; Nielsen, U.D.; Parunov, J.; et al. Loads for use in the design of ships and offshore structures. Ocean Eng. 2014, 78, 131-174. [CrossRef]

4. Jiao, J.; Ren, H.; Chen, C. Model testing for ship hydroelasticity: A review and future trends. J. Shanghai Jiaotong Univ. 2017, 22, 641-650. [CrossRef]

5. Sharma, R.; Kim, T.W.; Storch, R.L.; Hopman, H.; Erikstad, S.O. Challenges in computer applications for ship and floating structure design and analysis. CAD Comput. Aided Des. 2012, 44, 166-185. [CrossRef]

6. Bureau Veritas (BV). Design Sloshing Loads for LNG Membrane Tanks_Guidance Note NI 554 DT R00 E; Bureau Veritas (BV): Paris, France, 2010.

7. ITTC-Seakeeping Committee of the 28th ITTC. ITTC Quality System Manual Recommended Procedures and Guidelines-Procedure Sloshing Model Tests, Revision 00, Section: 7.5-02-07-02.7. Available online: https://ittc.info/media/7625/75-02-07-027.pdf (accessed on 27 December 2018). 
8. Lyu, W.; Moctar, O.E.; Potthoff, R.; Neugebauer, J. Experimental and numerical investigation of sloshing using different free surface capturing methods. Appl. Ocean Res. 2017, 68, 307-324. [CrossRef]

9. Song, Y.K.; Chang, K.A.; Ryu, Y.; Kwon, S.H. Experimental study on flow kinematics and impact pressure in liquid sloshing. Exp. Fluids 2013, 54, 1592. [CrossRef]

10. Ariyarathne, K.; Chang, K.-A.; Mercier, R. Green water impact pressure on a three-dimensional model structure. Exp. Fluids 2012, 53, 1879-1894. [CrossRef]

11. Chuang, W.L.; Chang, K.A.; Mercier, R. Impact pressure and void fraction due to plunging breaking wave impact on a 2D TLP structure. Exp. Fluids 2017, 58, 68. [CrossRef]

12. Kim, S.Y.; Kim, K.H.; Kim, Y. Comparative study on pressure sensors for sloshing experiment. Ocean Eng. 2015, 94, 199-212. [CrossRef]

13. Kim, K.-T.; Lee, P.-S.; Park, K.C. A direct coupling method for 3D hydroelastic analysis of floating structures. Int. J. Numer. Methods Eng. 2013, 96, 842-866. [CrossRef]

14. Wei, W.; Fu, S.; Moan, T.; Lu, Z.; Deng, S. A discrete-modules-based frequency domain hydroelasticity method for floating structures in inhomogeneous sea conditions. J. Fluids Struct. 2017, 74, 321-339. [CrossRef]

15. Yoon, J.S.; Cho, S.P.; Jiwinangun, R.G.; Lee, P.S. Hydroelastic analysis of floating plates with multiple hinge connections in regular waves. Mar. Struct. 2014, 36, 65-87. [CrossRef]

16. Lee, K.H.; Cho, S.; Kim, K.T.; Kim, J.G.; Lee, P.S. Hydroelastic analysis of floating structures with liquid tanks and comparison with experimental tests. Appl. Ocean Res. 2015, 52, 167-187. [CrossRef]

17. Klar, R.; Steidl, B.; Sant, T.; Aufleger, M.; Farrugia, R.N. Buoyant Energy-Balancing wind power and other renewables in Europe's oceans. J. Energy Storage 2017, 14, 246-255. [CrossRef]

18. Klar, R.; Steidl, B.; Aufleger, M. A floating energy storage system based on fabric. Ocean Eng. 2018, 165, 328-335. [CrossRef]

19. Gabl, R.; Achleitner, S.; Neuner, J.; Aufleger, M. Accuracy analysis of a physical scale model using the example of an asymmetric orifice. Flow Meas. Instrum. 2014, 36, 36-46. [CrossRef]

20. Hughes, S.A. Physical Models and Laboratory Techniques in Coastal Engineering; Advanced Series on Ocean Engineering; World Scientific: Singapore, 1993. [CrossRef]

21. Lykke Andersen, T.; Frigaard, P.; Damsgaard, M.L.; De Vos, L. Wave run-up on slender piles in design conditions - Model tests and design rules for offshore wind. Coast. Eng. 2011, 58, 281-289. [CrossRef]

22. Mavrakos, S.A.; Chatjigeorgiou, I.K.; Lentziou, D.M. Wave Run-Up and Second-Order Wave Forces on a Truncated Circular Cylinder Due to Monochromatic Waves. In Proceedings of the 24th International Conference on Offshore Mechanics and Arctic Engineering, Halkidiki, Greece, 12-17 June 2005; pp. 231-238.

23. Teh, H.M.; Venugopal, V.; Bruce, T. Hydrodynamic characteristics of a free-surface semicircular breakwater exposed to irregular waves. J. Waterway Port Coast. Ocean Eng. 2012, 138, 149-163. [CrossRef]

24. Tripepi, G.; Aristodemo, F.; Veltri, P. On-Bottom Stability Analysis of Cylinders under Tsunami-Like Solitary Waves. Water 2018, 10, 487. [CrossRef]

25. Peruzzo, P.; De Serio, F.; Defina, A.; Mossa, M. Wave Height Attenuation and Flow Resistance Due to Emergent or Near-Emergent Vegetation. Water 2018, 10, 402. [CrossRef]

26. Chiapponi, L.; Longo, S.; Tonelli, M. Experimental study on oscillating grid turbulence and free surface fluctuation. Exp. Fluids 2012, 53, 1515-1531. [CrossRef]

27. Caron, P.A.; Cruchaga, M.A.; Larreteguy, A.E. Study of 3D sloshing in a vertical cylindrical tank. Phys. Fluid 2018, 30, 082112.

28. Longo, S. Experiments on turbulence beneath a free surface in a stationary field generated by a Crump weir: Free-Surface characteristics and the relevant scales. Exp. Fluids 2010, 49, 1325-1338.

29. Longo, S.; Liang, D.; Chiapponi, L.; Jimenez, L.A. Turbulent flow structure in experimental laboratory wind-generated gravity waves. Coast. Eng. 2012, 64, 1-15.

30. Sellar, B.; Harding, S.; Richmond, M. High-resolution velocimetry in energetic tidal currents using a convergent-beam acoustic Doppler profiler. Meas. Sci. Technol. 2015, 26, 085801. [CrossRef]

31. Bonakdar, L.; Oumeraci, H.; Etemad-Shahidi, A. Run-up on vertical piles due to regular waves: Small-scale model tests and prediction formulae. Coast. Eng. 2016, 118, 1-11. [CrossRef]

32. Tosun, U.; Aghazadeh, R.; Sert, C.; Özer, M.B. Tracking free surface and estimating sloshing force using image processing. Exp. Thermal Fluid Sci. 2017, 88, 423-433. [CrossRef]

33. Bechle, A.J.; Wu, C.H. Virtual wave gauges based upon stereo imaging for measuring surface wave characteristics. Coast. Eng. 2011, 58, 305-316. [CrossRef] 
34. Gomit, G.; Chatellier, L.; Calluaud, D.; David, L. Free surface measurement by stereo-refraction. Exp. Fluids 2013, 54, 1540. [CrossRef]

35. Bregoli, F.; Bateman, A.; Medina, V. Tsunamis generated by fast granular landslides: 3D experiments and empirical predictors. J. Hydraul. Res. 2017, 55, 743-758. [CrossRef]

36. Chang, K.-A.; Liu, P.L.-F. Pseudo turbulence in PIV breaking-wave measurements. Exp. Fluids 2000, 29, 331-338. [CrossRef]

37. Fritz, H.M.; Hager, W.H.; Minor, H.E. Landslide generated impulse waves. 1. Instantaneous flow fields. Exp. Fluids 2003, 35, 505-519. [CrossRef]

38. Heller, V.; Bruggemann, M.; Spinneken, J.; Rogers, B.D. Composite modelling of subaerial landslide-tsunamis in different water body geometries and novel insight into slide and wave kinematics. Coast. Eng. 2016, 109, 20-41. [CrossRef]

39. Weigand, A. Simultaneous mapping of the velocity and deformation field at a free surface. Exp. Fluids 1996, 20, 358-364.

40. Park, J.; Im, S.; Sung, H.J.; Park, J.S. PIV measurements of flow around an arbitrarily moving free surface. Exp. Fluids 2015, 56, 56. [CrossRef]

41. Belden, J.; Techet, A.H. Simultaneous quantitative flow measurement using PIV on both sides of the air-water interface for breaking waves. Exp. Fluids 2011, 50, 149-161. [CrossRef]

42. Blenkinsopp, C.E.; Turner, I.L.; Allis, M.J.; Peirson, W.L.; Garden, L.E. Application of LiDAR technology for measurement of time-varying free-surface profiles in a laboratory wave flume. Coast. Eng. 2012, 68, 1-5. [CrossRef]

43. Montano, L.; Li, R.; Felder, S. Continuous measurements of time-varying free-surface profiles in aerated hydraulic jumps with a LIDAR. Exp. Thermal Fluid Sci. 2018, 93, 379-397. [CrossRef]

44. Weitbrecht, V.; Kühn, G.; Jirka, G.H. Large Scale PIV Measurements at the Surface of Shallow Water Flows. Flow Meas. Instrum. 2002, 13, 237-245. [CrossRef]

45. Akutina, Y.; Mydlarski, L.; Gaskin, S.; Eiff, O. Error analysis of 3D-PTV through unsteady interfaces. Exp. Fluids 2018, 59, 53.

46. Evers, F.M.; Hager, W.H. Videometric Water Surface Tracking: Towards Investigating Spatial Impulse Waves. In Proceedings of the 36th IAHR World Congress, Delft, The Netherlands, 28 June-3 July 2015; pp. 6618-6623.

47. Evers, F.M.; Hager, W.H. Spatial impulse waves: Wave height decay experiments at laboratory scale. Landslides 2016, 13, 1395-1403. [CrossRef]

48. Mignot, E.; Moyne, T.; Doppler, D.; Riviere, N. Clear-water scouring process in a flow in supercritical regime. J. Hydraul. Eng. 2016, 142, 04015063-1. [CrossRef]

49. Przadka, A.; Cabane, B.; Pagneux, V.; Maurel, A.; Petitjeans, P. Fourier transform profilometry for water waves: How to achieve clean water attenuation with diffusive reflection at the water surface? Exp. Fluids 2012, 52, 519-527. [CrossRef]

50. Heller, V.; Spinneken, J. On the effect of the water body geometry on landslide-tsunamis: Physical insight from laboratory tests and 2D to 3D wave parameter transformation. Coast. Eng. 2015, 104, 113-134.

51. Whittaker, C.N.; Fitzgerald, C.J.; Raby, A.C.; Taylor, P.H.; Orszaghova, J.; Borthwick, A.G.L. Optimisation of focused wave group runup on a plane beach. Coast. Eng. 2017, 121, 44-55. [CrossRef]

52. Niedzwecki, J.M.; Duggal, A.S. Wave runup and forces on cylinders in regular and random waves. J. Waterway Port Coast. Ocean Eng. 1992, 118, 615-634. [CrossRef]

53. Kang, Z.; Ni, W.; Zhang, L.; Ma, G. An experimental study on vortex induced motion of a tethered cylinder in uniform flow. Ocean Eng. 2017, 142, 259-267. [CrossRef]

54. O'Connell, K.; Thiebaut, F.; Kelly, G.; Cashman, A. Development of a free heaving OWC model with non-linear PTO interaction. Renew. Energy 2018, 117, 108-115. [CrossRef]

55. Sjökvist, L.; Wu, J.; Ransley, E.; Engström, J.; Eriksson, M.; Göteman, M. Numerical models for the motion and forces of point-absorbing wave energy converters in extreme waves. Ocean Eng. 2017, 145, 1-14. [CrossRef]

56. Usherwood, J.R. The aerodynamic forces and pressure distribution of a revolving pigeon wing. Exp. Fluids 2009, 46, 991-1003. [CrossRef] [PubMed]

57. Gyongy, I.; Richon, J.-B.; Bruce, T.; Bryden, I. Validation of a hydrodynamic model for a curved, multi-paddle wave tank. Appl. Ocean Res. 2014, 44, 39-52. [CrossRef] 
58. Draycott, S.; Noble, D.; Davey, T.; Bruce, T.; Ingram, D.; Johanning, L.; Smith, H.; Day, A.; Kaklis, P. Re-creation of site-specific multi-directional waves with non-collinear current. Ocean Eng. 2018, 152, 391-403. [CrossRef]

59. Draycott, S.; Sutherland, D.; Steynor, J.; Sellar, B.; Venugopal, V. Re-creating waves in large currents for tidal energy applications. Energies 2017, 10, 1838. [CrossRef]

60. Draycott, S.; Davey, T.; Ingram, D.M. Simulating Extreme Directional Wave Conditions. Energies 2017, $10,1731$.

61. Ingram, D.; Wallace, R.; Robinson, A.; Bryden, I. The design and commissioning of the first, circular, combined current and wave test basin. In Proceedings of the Oceans 2014 MTS/IEEE Taipei, Taiwan, 18-21 May 2015.

62. Sutherland, D.R.J.; Noble, D.R.; Steynor, J.; Davey, T.; Bruce, T. Characterisation of current and turbulence in the FloWave Ocean Energy Research Facility. Ocean Eng. 2017, 139, 103-115. [CrossRef]

63. Draycott, S.; Sellar, B.; Davey, T.; Noble, D.R.; Venugopal, V.; Ingram, D. Capture and Simulation of the Ocean Environment for Offshore Renewable Energy. Renew. Sustain. Energy Rev. 2019. under review.

64. MARINET (2012) Work Package 2: Standards and Best Practice-D2.1 Wave Instrumentation Database. Revision: 05. Available online: http://www.marinet2.eu/wp-content/uploads/2017/04/D2.01-WaveInstrumentation-Database.pdf (accessed on 23 November 2018).

65. Heller, V.; Chen, F.; Brühl, M.; Gabl, R.; Chen, X.; Wolters, G.; Fuchs, H. Large-scale experiments into the tsunamigenic potential of different iceberg calving mechanisms. Sci. Rep. 2018. [CrossRef]

66. Mai, T.; Greaves, D.; Raby, A.; Taylor, P.H. Physical modelling of wave scattering around fixed FPSO-shaped bodies. Appl. Ocean Res. 2016, 61, 115-129. [CrossRef]

67. Wienke, J.; Oumeraci, H. Breaking wave impact force on a vertical and inclined slender pile-Theoretical and large-scale model investigations. Coast. Eng. 2005, 52, 435-462. [CrossRef]

68. EDL-Edinburgh Designs Ltd. Available online: http://www.edesign.co.uk/product/wavegauges/ (accessed on 23 November 2018).

69. Andersen, T.L.; Frigaard, P. Horns Rev II, 2D-Model Tests: Wave Run-Up on Pile. In DCE Contract Reports, No. 3; Department of Civil Engineering, Aalborg University: Aalborg, Denmark, 2006.

70. Liu, H.-T.; Katsaros, K.B.; Weissman, M.A. Dynamic response of thin-wire wave gauges. J. Geophys. Res. 1982, 87, 5686-5698. [CrossRef]

71. Petti, M.; Longo, S. Turbulence experiments in the swash zone. Coast. Eng. 2001, 43, 1-24.

72. Bruce, T.; van der Meer, J.W.; Franco, L.; Pearson, J.M. Overtopping performance of different armour units for rubble mound breakwaters. Coast. Eng. 2009, 56, 166-179. [CrossRef]

73. Pullen, T.; Allsop, W.; Bruce, T.; Pearson, J. Field and laboratory measurements of mean overtopping discharges and spatial distributions at vertical seawalls. Coast. Eng. 2009, 56, 121-140. [CrossRef]

(C) 2018 by the authors. Licensee MDPI, Basel, Switzerland. This article is an open access article distributed under the terms and conditions of the Creative Commons Attribution (CC BY) license (http:// creativecommons.org/licenses/by/4.0/). 